Cumhuriyet International Journal of Education-CIJE

e-ISSN: 2147-1606

Vol 5 (USOS Özel Sayı), 2016, 72 - 81

\title{
The Examination of Behaviors of Primary and Secondary School Teachers' Learner Autonomy Support
}

\author{
Salih UŞUN, Ali YAKAR, Orhan KAHYA
}

\begin{abstract}
Summary
The notion of learner autonomy comprises both students' skills of independent studying and identifying their needs and goals, also the processes like organization and evaluation of learning. Creating environments helpful for learner autonomy is highly related with teachers' effectiveness on teaching-learning process. That is to say, students are expected to have responsibility on their own learnings, apply and evaluate their learning skills. Learning outcomes included in curriculum goals are intended to perform at the end of the teaching-learning process. In order to carry out these outcomes, creating a proper learning environment is substantial. Provided that, convenient teaching process can be realized on the bases of curriculum needs and content. Learning environment vary from physical condition, teaching materials, subject to even course. For instance a classroom and the materials used for language teaching is different from the one used a for science teaching. If a classroom to be designed for any courses or subjects, such learning environment should have enriched stimulants, meet the needs and be functional. The learning environment, physical conditions and materials should both appeal to and make sense on students while they should be coherent and instructive with the goals. At this point, teachers are responsible for the best outcomes of learning environment and the materials. Teaching process should be promoting to learner autonomy. Likewise, teachers have a significant role in promoting students' learner autonomy. Furthermore, defining teachers' views on promoting learner autonomy is a crucial topic to be studied.

The purpose of this study is to investigate and compare promoting learner autonomy behaviors of primary education teachers and subject teachers working at secondary schools. The research was designed in quantitative survey model. Promoting learner autonomy behaviors of primary education teachers and subject teachers were compared. 51 primary school and 162 secondary school teachers in Denizli comprise the sample of the survey. Promoting Learner Autonomy Scale (Oğuz, 2013) was used as data gathering tool of the research. Descriptive Statistics, T-test for pair comparisons, Mann Whitney U, correlation analysis and ANOVA for three or more comparisons were used to define the levels of teachers' promoting learner autonomy behaviors. Findings of the study show that teachers' views on the necessity of promoting learner autonomy behaviors become prominent. By contrast, their behaviors on promoting learner autonomy are found to be at middle level. The study results show that there is not significant difference between teachers' views on promoting learner autonomy behaviors and their promoting behaviors. Although there isn't statistically significance between the subject teachers' views and promoting behaviors on learner autonomy, the findings show significant results among promoting learner autonomy behaviors of the subject teachers.
\end{abstract}

